\title{
Challenges Companies Encounter When Delivering Sustainable Solutions: Research Conducted in the United Arab Emirates
}

\author{
Marek Seretny ${ }^{1,2^{*}}$, Asli Cazorla Milla ${ }^{1}$, Muhammad Azeem ${ }^{1}$, Deepika Gaur ${ }^{1}$, Dennis Jones ${ }^{1}$, and \\ Rabeb Ben Abdallah ${ }^{1}$ and Leonardo Jose Mataruna-Dos-Santos ${ }^{1,3}$ \\ College of Business Administration, American University in the Emirates. \\ 2 Faculty of Management, Warsaw University of Technology; \\ 3 Centre for Trust, Peace and Social Relation, Coventry University \\ *Correspondence: email: marekseretny@me.com Tel: +971 4499612
}

\begin{abstract}
The purpose of this article is to draw attention to the challenges faced by business organizations implementing sustainable solutions in the United Arab Emirates (UAE) and the wider Gulf Coast Countries (GCC) region. To this end, our study examines an academic theory supporting the implementation of responsible solutions to the market. Ultimately, the authors hope to inspire the reader to consider what he or she can do to ameliorate the existing challenges encountered by sustainable businesses. The analysis presented in this article implies that in recent markets, the implementation of the sustainability theory is essential for further development. The research project contributes to the increase of knowledge about corporate and organizational challenges related to running a responsible business, as well as challenges related to the application of environmental, social and economic aspects of sustainable business practices. The research is currently limited to conceptual analysis, literature review and a survey conducted during the Sustainability Week 2019 in Abu Dhabi, United Arab Emirates. Nevertheless, this is the first stage of the research project conducted by the research team in cooperation with enterprises that implement responsible solutions in many global markets, and in UAE market. The scope of the first stage of the study was limited to the analysis of data clarifying the concept of the model specified in the research. To prove the validity of the model it will be implemented and tested in cooperation with organizations participating in the research.
\end{abstract}

Keywords: sustainability; sustainable development; sustainable marketing

\section{Introduction}

The inhabitants of every continent, region, and country cannot avoid the unpleasant truth: Earth seems to have become insufficient to meet the standards of living societies expect [1]. Proponents offer sustainable development - usually defined as delivering a high quality of life for current and future generations - as the primary solution. The list of governments, international organizations and NGOs championing sustainable development expands annually. Still, companies striving to offer sustainable solutions, with a sincere commitment to responsibility towards society, the natural environment and the economy (people, planet, profit - the Triple Bottom Line of Sustainability) face numerous challenges.

Scholars and business practitioners seeking to offer solutions to the impediments faced by sustainable businesses have failed to reach a consensus on both the underlying factors and optimal solutions. Such a development is not surprising given the complexity of the issues. While the precise list of factors challenging sustainable business may not be settled, experts categorize the obstacles as either internal or external to the organization. They also generally categorize the factors as economic, marketing, socio/psychological, legal, or environmental. In terms of solutions, academics and 
businesspersons advocate three primary strategies: sustainable mindsets, sustainable business models, and sustainable marketing.

This paper presents a study on the challenges faced by companies offering sustainable solutions in the United Arab Emirates (UAE). In stark contrast to many jurisdictions, the government of the UAE strongly advocates sustainable development and incorporates the concept into its strategic initiatives. Theoretically, the UAE ought to be a fertile territory for sustainable businesses. Even so, companies offering sustainable solutions in the UAE experience challenges. We postulated on the key challenges faced by sustainable businesses after informally interviewing managers of over 60 companies in the UAE and tested our hypotheses against survey results.

\section{Sustainability in the UAE}

From an academic point of view, studying sustainable development in the UAE presents a unique opportunity. According to the KPMG Lower Gulf Limited [2], "the UAE is focused to establish its presence as a global sustainability leader". Despite this aspiration, the UAE has substantial room for improvement on its sustainability measurements. The country scored a 77 on the 2018 Environmental Performance Index (EPI), which ranks 180 countries on 24 performance indicators across ten issue categories covering environmental health and ecosystem vitality [3]. Thus, the business conditions in the UAE include a government actively promoting sustainable development and significant market opportunities for sustainable solutions.

UAE government policies emphasizes the importance of sustainability in the development of the country. The "Green Economy for Sustainable Development" initiative has been launched since 2012. Government policies emphasizes that sustainability is the basis for the success of the country's economy, it also provides the basis for effective competition of the UAE's economy in the international arena. The assumptions of the Green Economy are built on six pillars: 1) Green energy - production and use of renewable energy; 2) Government policies that encourage investments in green economy and to facilitate the production, import, export and re-export of green products and technologies; 3) Environment preservation in relation to urban planning and efficiency in environmentally friendly housing and building; 4) Dealing with the effects of climate change by promotion of organic agriculture, maintain biodiversity and protect the ecological balance; 5) Rationalization in the use of water resources, electricity and natural resources and recycle waste; and 6) Development and promotion of green technology.

The unique situation in the UAE raised several questions. As researchers, we wondered to what extent government objectives translated into fostering companies offering sustainable development in the private sector. Are organizations (operating in the local market and those attempting to enter it) aware of the directions of UAE sustainable development? Are sustainable companies able to compare the legal conditions for sustainable development between their home market and the UAE market? What is the awareness of sustainable development at the operational level, at the level of the market for small and medium-sized enterprises? Are there any external psychological barriers inhibiting the implementation of sustainable solutions? Is the traditional marketing approach able to fully support the implementation of sustainable market solutions? In short, what challenges do sustainable businesses still face in a business environment purportedly favorable for sustainable development.

\section{Literature review}

During the first stage of the project - unstructured interviews with business representatives during the Abu Dhabi Sustainability Week - we learned the most important problems participants faced were related to the concepts of responsible business, the legal environment, and how to foster a change of thinking both clients and managers. In addition, the need to introduce a change in marketing practices was of significant importance in conversations with business. During the interviews respondents also indicated elements of the business environment that matter when implementing responsible products and services. They highlighted the importance of the internal factors related to their businesses and those related to the external environment embedding them in 
the UAE market reality related to sustainable development. In the following literature review we concentrate on the issues participants highlighted in their interviews.

\subsection{Sustainable Business concept}

Re-examined business models should address economic, social and environmental elements to provide an empirically grounded basis for relevant business practice. Hogevold [4], argue that the existing business practice do not adequately take into account the fact that the Earth is the ultimate stakeholder and source, where everything begins and ends. This unfortunate business approach leads to the development of management theory and practice, which may be irrelevant and unimportant in the near future. To the best of our knowledge, we agree that this assumption is unfortunately widespread in existing management theory and underpins previous research conducted in the business context.

As stated by the Network for Business Sustainability, sustainable business is a necessary condition for further development. Such perspectives provide the company greater innovation and continuous development, which will bring more benefits to the whole society. [5, 6] highlight the importance for the company to create value which combines the development of society with the economic development $[7,8,9]$. To create this value, management should understand and implement new strategies. $[10,11]$ They also should articulate values and undertake ethical decisions and responsible behaviors no matter the outcome.

On the other hand, employees also have a crucial role in the company's development of sustainable business. Managers must inform their employees about all the environmental and pro-social activities conducted by the company, with an aim to ensure the success of these activities. [5] Integrating the corporate level with the lower level has a significant impact on enforcing appropriate knowledge and acceptable behaviors. The role of managers is to create an environment for the company's sustainable development.

Schneider and Clauss [12] discussed from their view of five characteristics of sustainable business models: organic development, collective effort, value-based actions, interaction of sustainability dimensions and distinct group of target customers. The authors emphasized the social, economic and ecological dimensions to provide one value potential in the sustainability community. Svejvig [13] mentioned that based on acceleration of time is possible to find serious and important challenge for today's organization in order to achieve project values differences. According to the authors, there are some main reasons for the differences: valuing speed, project ownership, timing of the project methodology introduction, the nature of the project, and the institutional context and governance structures.

Continuing thoughts of the quoted scholars, we want to emphasize that sustainability becomes a strategic management imperative. Economic development that does not take into account the philosophy of sustainability leads humanity to nowhere. Researchers, businesspeople and policymakers need to work together to make sustainability a permanent element in the development of science, social and economic life.

\subsection{Sustainable mindset}

The implementation of the sustainability concept, both on the market and in business operations, requires a change in the way of thinking. As Einstein [14] emphasized "We can't solve problems by using the same kind of thinking we used when we created them." Many of the problems that humanity is currently struggling with are due to the set of values that humankind is guided by, one of them is consumption. It can be argued that consumption is the most important value of the twenty-first century - indisputably, it is the driver of today's economy. Regardless of the level of socio-economic development, entire nations and individual citizens strive to increase consumption - unfortunately it leads in a straight line to overconsumption. Overconsumption which is a symbol, hallmark of today's world.

Scientific studies provide ample evidence that, human consumption has already exceeded the regenerative capacity of the planet due to the large scale of economic activity dedicated to continuously 
degrading the natural environment [15]. These are not problems related to the issue of technical structure, which requires engineering, physics and chemistry to provide solutions. But problems mainly are erupting from unsustainable human behavior and can be reversed by changing the human behavior [16].

As, innovative technologies can solve the problem of efficient use of resources only partly; to achieve a sustainable society basic change in everybody's behavior and particularly change in values, attitudes, beliefs are required [7, 17]. According to Kassel, [18] "a sustainability mindset is intended to help individuals analyze complex management challenges and generate truly innovative solutions".

The definition given by Brundtland [19]: 'meeting the needs of present generations without compromising the needs of future generations to meet theirs', emphasis the impact of mindset of people to think for future generations. The sustainable issue could be economical, environmental, social but is emerging out of the gap of human knowledge and discrepancy in behavior which refers to the misunderstood human perspective [20]. The capacity to analyze and evaluate the demand of environment and to bring the changes in behavior seems limited.

The opposition to change toward sustainability is the mindset of an individual which frames the society. The resistance to change postpones the action until the environmental damage becomes irreversible, the support belief in technology alone to save the environment creates the sense of ignorance towards self-action [21].

As human beings, intellectual domain does not remain in shackles of the mindset and has the power to break the barriers and overcome the difficulties. The new trends of positive psychology analyzed human strengths [22]. However, psychological research proved that only awareness is not sufficient to motivate people to perform action in favor of sustainable development [20].

The emotional connectedness of people towards the social and environmental factors is a positive mindset to bring the sustainable development. Conscious awareness and attended efforts for the welfare of life around is enhancing the wellbeing and contributing to positive changes for the enrichment of the entire planet [20].

The sustainability mindset cut the continues tendencies and breaks away from conventional organization or traditional management disciplinary silos promoting the integration of management of "ethics, entrepreneurship, environmental studies, systems thinking, self- awareness and spirituality within the dimensional contexts of being (values), thinking (knowledge) and doing (competency)", [18].

\subsection{Sustainable marketing}

Marketing plays a key role in the management activities of a modern business. Economic development takes place with the active participation of marketing. The world is going through the dynamic changes. The traditional marketing approach is not adequate anymore to address all changes taking place on the contemporary market, and in addition marketing conducted traditionally is increasingly criticized [23]. Many groups of customers rightly criticize marketing - for generating a widespread over-consumption resulting with all the negative consequences for humanity, created by deceptive marketing practices, planned obsolescence. Traditional marketing is criticized for its negative impact on society - such as civilization health disorders, false wants and materialism, decreasing of the social goods and cultural pollution. Taking this into account, it is clearly observable that the field of marketing needs to reexamine its own conceptual models [24].

Gordon [9] note marketing has prospered to serve the consumers and societies' needs in an environment where governments, societies and businesses have created. [25, 26] goes further and claims that marketing is transforming in response to the new dynamics in the market environment. Companies expanding their focus from products through the customers up to humankind issues. 
For more than three decades, researchers have investigated and theorized the responsible efforts of the companies. The stages of sustainability marketing and the authors who significantly contributed to the literature are summarized in Figure 1.

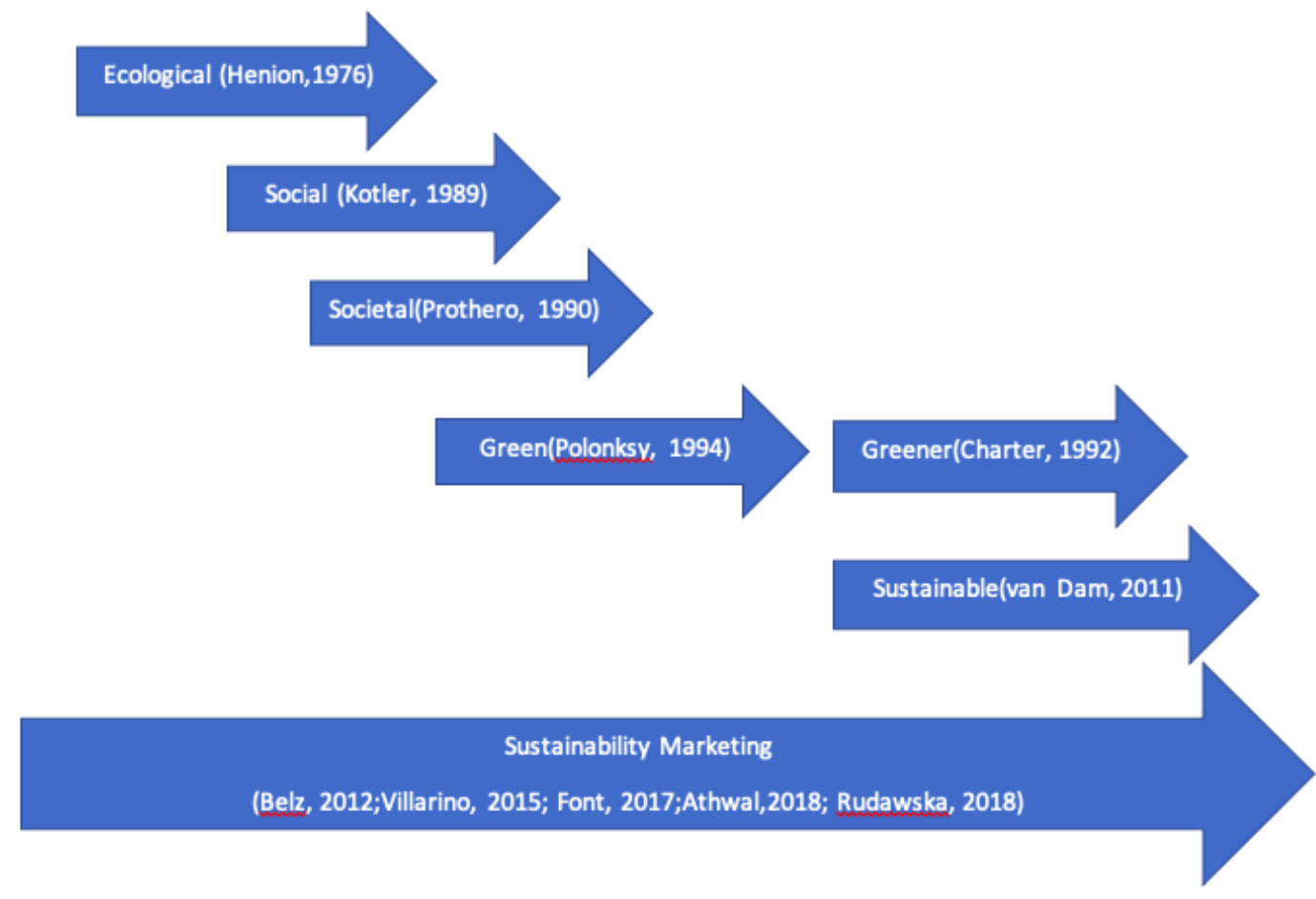

Figure 1. Evolution of Sustainability Marketing

Communicating sustainability efforts can be achieved via branding. Brands that pass along their green initiatives through appropriate channels earn the trust and confidence of their customers. The aim of any brand is to develop a long-lasting relationship in alignment with their marketing efforts. New spender groups like millennials and Gen $\mathrm{Z}$ do care about consuming products and services that are sustainable. A recent survey done by Nielsen to millennials indicated that $66 \%$ of consumers would spend more on a product if it came from a sustainable brand. This notion becomes crucial while developing overall marketing communication strategy. It is inevitable to recognize that consumers are looking out for sustainable brands [27].

\subsection{Legal environment}

Generally, businesses offering sustainable solutions face a large and complex array of legal environments. Like every business, each company must comply with its own local, regional, and national laws and regulations. If expanding into a foreign market, the company must comply with the local, regional, and national laws of the foreign jurisdiction. For companies offering sustainable solutions, the legal environment potentially includes hundreds of conventions, multinational treaties, declarations of states, resolutions of international organizations, programs of action, and codes of conduct. Determining the legal effect of such instruments and the implementations of international treaty regimes on domestic regulations and practices are particular challenges.

Legally, the definition of sustainable development is well-defined and the product of a vast UNled promotion operation over the last three decades [28]. The UN articulated the current legal definition in 1997, when the UN General Assembly held a special session (Rio +5) to appraise the status of Agenda 21, the sustainable development agenda established at the UN Conference on Environment and 
Development (Earth Summit) held in Rio de Janeiro on June 13, 1992. Accordingly, the well-quoted definition of sustainable development set out in the Brundtland Report (1987), "development that meets the needs of the present without compromising the ability of future generations to meet their own needs" was imbued with two axiomatic core concepts: intergenerational and intragenerational equity. [28]. When integrated, the concept of sustainable development encompasses environmental protection, economic development, and social development.

While the legal definition of sustainable development is fixed, standards related to the concept are necessarily dynamic, as they are inherently tied to social, environmental, and scientific evolutions. Thus, what is determined to be sustainable development will change over time. The malleability of the concept has generated considerable criticism. Some critics have charged the concept to be void of substance or incapable of proper legal classification. Regardless, UAE government policies emphasize the importance of sustainability in the development of the country and adopt the UN's definition of sustainability.

UAE's Green Economy policy, mentioned above, initiated further sustainable agendas, of which the most important is the UAE Vision 2021. The Vision includes a set of long-term indicators reflecting the UN Global Sustainable Development Goals (see Figure 2). UAE National Agenda 2021 shows that the country is committed to sustainable development by setting the following national priorities: Cohesive Society and Preserved Identity; Safe Public and Fair Judiciary; Competitive Knowledge Economy Driven by Innovation, First-Rate Education System, World-Class Healthcare, Sustainable Environment and Infrastructure. National Agenda 2021 aims to drive sustainable development while preserving the environment and achieving a perfect balance between economic and social development [2].

The policies establish significant sustainable goals. For example, UAE government set a $50 \%$ target for clean energy in the country and to cut carbon dioxide emissions by $70 \%$ by 2050 in its UAE Energy Strategy 2050. The strategy also contemplates the improvement of energy efficiency by $40 \%$ in this given time [29].

Another government inspired driver of sustainable development is the National Innovation Strategy, launched in 2014, positioning the UAE as one of the world's most innovative nations. The framework for the strategy is structured around the following priority sectors: renewable energy, transport, education, health, technology, water and space.

There are also governmental developments on the individual Emirates level, including but not limited to Expo 2020 in Dubai, Abu Dhabi Economic Vision 2030, Dubai Plan 2021, Dubai Integrated Energy Strategy 2030, Dubai 10X Goals, Dubai Green Building Regulations, Estidama building rating systems, Environment Protection and Development Authority (Ras Al Khaimah) Strategic Plan, and Sharjah Environment and Protected Areas Authority Strategy. 


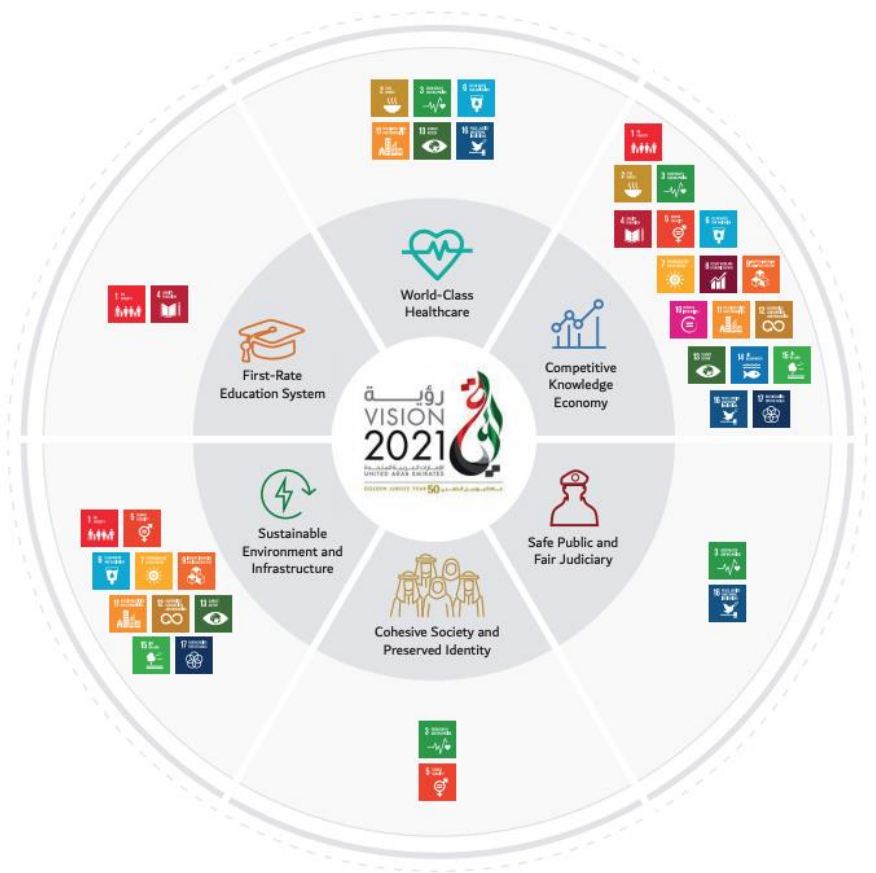

Figure 2. Mapping of SDG's to UAE's National Agenda 2021

The high level of government activity indicates a clear vision within the UAE to create a truly sustainable future [2]. Based on the emirate and federal governmental strategies, visions and proclamations, along with business incentives and academic initiatives, the researchers assumed opening and operating a sustainable business should not be an exceptionally difficult challenge in the $\mathrm{UAE}$, beyond the normal challenges faced by any business.

\section{Research Methodology}

The explorative research design was adopted to understand the perceived challenges responsible firms (organizations delivering sustainable solutions) face in the UAE market. The research sample was built on the basis of contacts with companies participating in the "Sustainability Week" event organized in January 2019 in Abu Dhabi UAE. Abu Dhabi Sustainability Week 2019 (ADSW) is a global platform that addresses the interconnected challenges that effect the widespread implementation of sustainable development. Participants represented a broad spectrum of industries, from waste management, through proposals for clean water, energy to ecological farming and sustainable construction.

\subsection{Framework of the research}

The scientific considerations and research results presented in this article are aimed at drawing attention to the complexity of the challenges related to the implementation of the sustainable market solutions in the Middle East - specifically considering UAE business environment. The present research was conducted with the involvement of enterprises participating in Sustainability Week 2019 in Abu Dhabi.

The theoretical framework explains the various components underlying the constructs that lead to the viability of businesses dealing in responsible solutions implementation. The framework focuses on internal, business-related factors, which can explain the performance of responsible businesses operating in the UAE market. These include corporate governance, marketing and economic factors. There are also factors which explain the external environment, which include legal, psychological, geographic/natural environment and social factors. The perceived effects of these factors were 
examined on the degree of sustainability of businesses dealing with the implementation the responsible solutions on the UAE market.
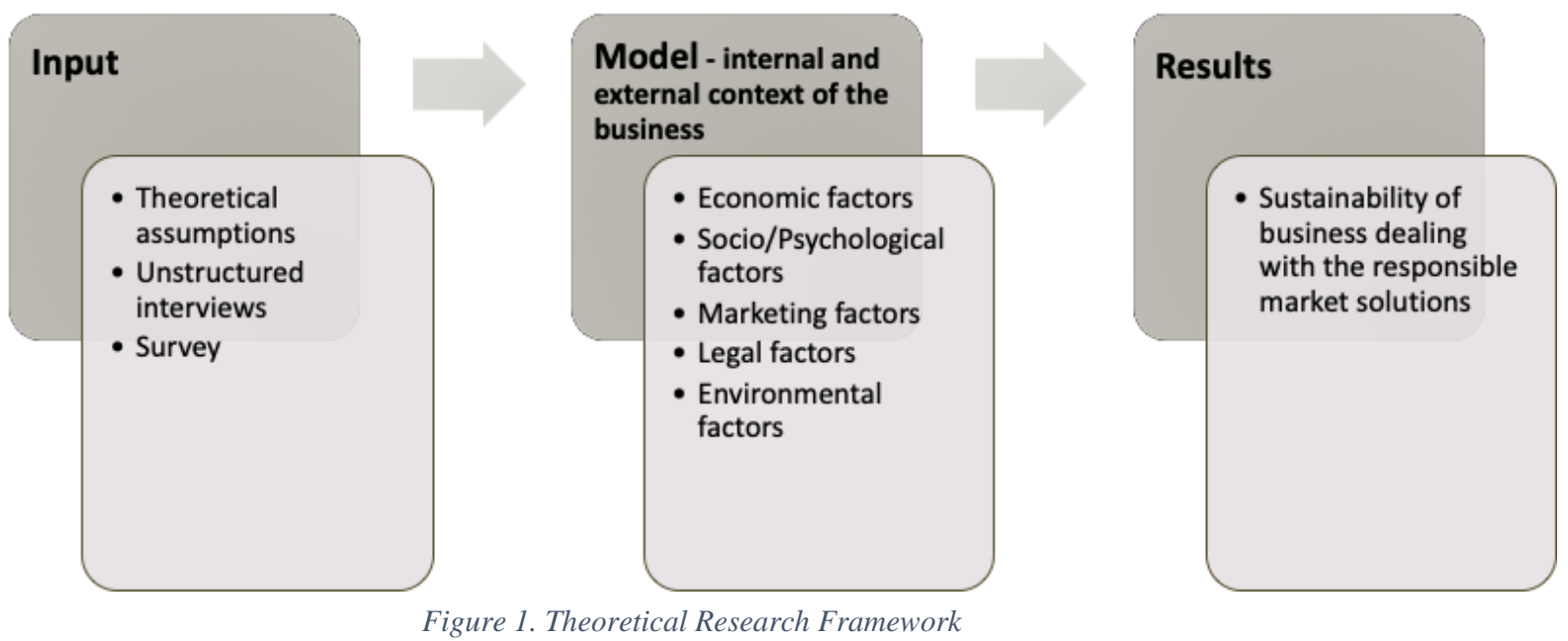

The research has been limited to the question of what challenges do enterprises face when implementing responsible market and business solutions in the UAE? The following hypotheses were developed to obtain the research objectives:

H1: Companies endeavoring to compete in the sustainable market sector believe the UAE legal environment is favorable.

H2: Companies consider economic, socio-cultural and environmental factors to be highly significant in sustainable development of UAE market.

H3: Psychological barriers inhibit the implementation of sustainable solutions in the UAE.

H4: The conventional marketing approach hinders the ability to implement successful sustainable solutions in the UAE.

A two-stage survey was conducted to collect data. The first stage was based on direct unstructured interviews with a "Sustainability Week" participants in Abu Dhabi. The second stage was conducted based on a questionnaire, which was designed to gather evidence that can help in the development of marketing strategic solutions for achieving sustainability goals of the businesses dealing in sustainable goods and services.

In the first stage, researchers conducted unstructured interviews with 68 different organizations. Participants presented their eco-innovations, clean production proposals and sustainability-oriented innovations which integrate ecological and social aspects into their products, processes and organizational systems. Unstructured interviews outline the situation and context, intending to make the interviewee feel relaxed by creating an informal atmosphere [30]. In unstructured interviews, the respondents and interviewer engage in a conversation with open-ended questions allowing the respondent to open-up and communicate in their own way. Unstructured interviews, sometimes referred to as discovery interviews, are adaptable in their nature, thus they do not require a set of predetermined questions [31]. They are used to generate qualitative data and they have increased validity because the method allows the interviewer to have a deeper understanding of the situation.

There are limitations of using unstructured interviews. The amount of time is such a limitation. Conducting the interview and analyzing the data can be very time consuming compared to 
structured interviews. Unstructured interviews were appropriate to use in this research since it served as an important preliminary stage to develop the actual survey.

In the second stage, responses from 39 companies were analyzed and presented in the following section. Section-1 collected demographic information, the statements in section-2 gathered the participant's perception about the UAE and their home country markets where applicable (measured on a five-point Likert scale), and in the section-3, a few open-ended questions were asked to gather qualitative data about the market. The research instrument was sent to the 68 companies that attended meetings at Sustainable Week and that were interested in participating in the study.

Thirty-nine companies completed the online questionnaire. Issue of missing values was managed by applying mandatory fields in the Google Forms, which disallowed respondents to submit a response with any unfilled section. Five unengaged responses were observed and deleted from the data. The final data set had 37 cases which were included in the study. The sample size is a significant limitation. A greater generalizability of the results may be achieved with a larger sample size.

\section{Data analysis}

During the first stage of the research, direct unstructured interviews were conducted. This unstructured interview session occurred at the time of informal meeting in sustainable week. Companies participating in Sustainable Week bemoaned the fact that the use of sustainable resources by them was not showing an impact in the market due to the unreadiness of the market for such methods. In the discussion, we observed many representatives of the sustainable week were expatriates and this gave an insight over the impact of expatriates in the country. Due to the higher percentage of expatriates in UAE population, expatriates represent decision-making management and consumers both in large number. This has a direct influence on the implementation and success of any new trend. The UAE is a global business hub. Its policy makers and business owners are well equipped with financial and energy resources, with strong backing or support by Government in the business processes, so it is a matter of research that how much response they will give on new trends which are causing threat to their existing establishment and the way of doing business even though the new trends may be cheap and can be implemented for further cost reduction.

The workforce of Dubai from the lower to the middle level are generally expatriates. Thus, the process of hiring resources with different or modern skillset is complex and lengthy and typically includes advertisement, travel, and selection of suitable candidates who are ready to migrate abroad. In this region, status symbols are important, and consumers keep this in mind when buying and using product. It seems that status symbol is also reflected in business as UAE is a tourist spot which recorded up to 16 million in Dubai and 2 million tourists in Abu Dhabi in year 2018, which can roughly be estimated as 17-18 million tourists per year wherein the population of the UAE is approximately 10 million, this is a very big aspect which shows that it is difficult to implement any new trend which seems not to be tourist friendly. Tourist industry cannot be ignored as it plays an important role in the economy. It is also observed that business owners and policy makers are either from UAE or are partners in the business, so this aspect is also to be considered as the region has greater inclination towards culture and tradition. Although the region is very flexible for business environment and friendly with technology changes but as they respect the tradition, culture and customs but may also have resistance towards any new trend which may adversely affect the culture and tradition.

During the first stage of the research we learned respondents often compare the market situation in their own country with the UAE market. We also noticed that the representatives of enterprises are not informed and to some extent do not recognize the directions of UAE's sustainable development goals.

The most discussed topics by business representatives were legal and business conditions both at the home and foreign markets. However, the majority of interviews were dominated by discussion about marketing and its impact on the success of implementing sustainable solutions on global markets, including the UAE market. The unstructured interviewed allowed the researchers to 
compile a set of issues which became the basis of the questionnaire used in the second stage of the research.

\subsection{Demographic Information}

The following section details various demographic information regarding the 37 survey respondents. For the data analysis, we used R programming for generating graphs and calculations [32].

\subsubsection{Distribution of locations of the head office}

The majority of companies in this study have an office inside the UAE. About $13 \%$ of the companies have offices both inside and outside the UAE. This indicates companies dealing in sustainable goods and services generally feel the need for a permanent physical presence in the local market to sell sustainable solutions. This also indicates a direct connection with their customers is considered important by the participating companies. It also suggests office space in the UAE market is attractive for companies implementing new sustainable solutions.

The single largest majority group is set of those firms which have their head office in the UAE. This shows that they operate through the local head office in UAE. This supports the evidence that companies prefer to be in direct contact with the customers. This also provides evidence that locally established companies find convenience to operate in this market compared to foreign companies. This is also an indication that any foreign company operating in UAE has significant competition with locally operated firms. Foreign companies participating in this study were from Germany, South Korea, Italy, South Africa, and Angola.

Most of the firms were exclusively dealing in their own brands. About $30 \%$ of the companies were selling the products of other companies alongside their own brands. Twenty four percent of the companies are only distributing and selling other companies' products. Additional data is required to understand the role of these firms as a distributor or retailer, which is not clear in the current data.

\subsubsection{Commitment to sustainable business}

There are about $11 \%$ newly established companies in this study (see Figure 4 ). Also, about $11 \%$ of the companies have one to three years of experience in the sale of these products. There are about $19 \%$ companies which have more than three years of experience. The number of newly established company may increase due to mega-event in next year Expo-2020. The UAE Government is encouraging foreign companies to enter the country. Majority about $60 \%$ companies have more than five years of experience.

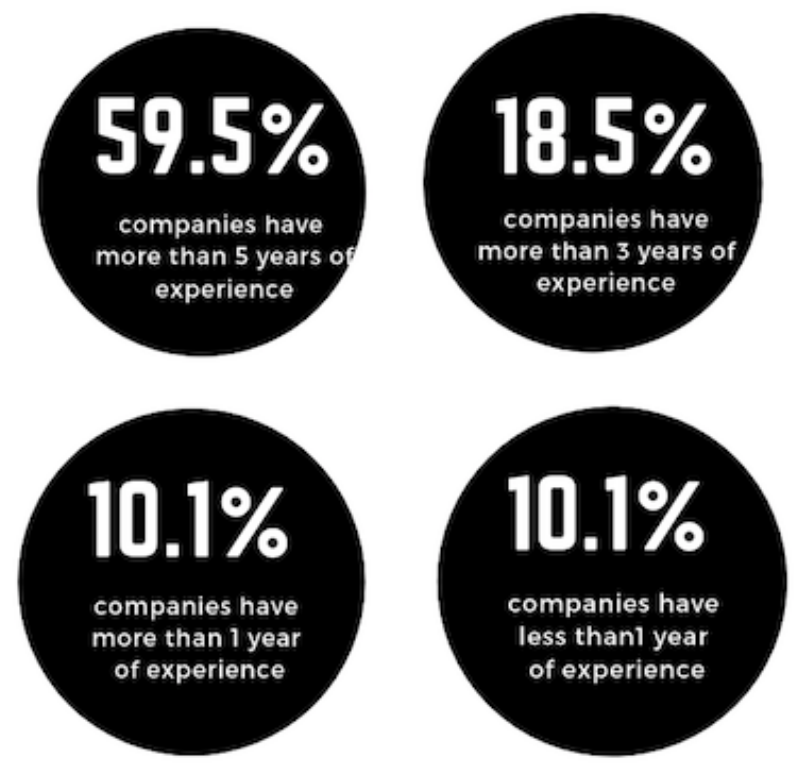

Figure 2. Distribution of experience in dealing with the sustainable solutions 
The presence of more established $(5$ years + ) businesses indicates awareness about the sustainable goods is increasing among the Middle East customers, and they are creating potential market which has attracted the investors to capitalize in this area. This result also indicates that there is an understanding regarding the UAE government policies supporting implementation of sustainable, socially and environmentally-friendly goods and services.

Clear cut line cannot be drawn on the size of the companies. Number of employees in $32 \%$ companies were above 500, which brings them in the category of large size firms based on the criteria of number of employees. Rest $68 \%$ are SMEs in this range. Therefore, it can be assumed that these SMEs in the region are also contributors to sustainable development, which coincides with the research carried out [33]. Authors state in their article that the last decade has begun to generate broad knowledge on the specificities of sustainability-oriented innovations in small and medium sized enterprises as they are increasingly recognized as central contributors to sustainable development. On the base of our research findings we can state that the similar pattern could be present in this region. Based on direct interviews conducted during the 2019 Sustainability Week we identified that sustainable innovation practices include both product and services offers as well as processes and organizational practices. We also find that the presented offers focused on eco-innovations rather then on innovations based on covering a triple bottom line of sustainability perspective (economic, social and environmental dimension).

In the following section, the analysis has provided the information about the degree of agreement or disagreement on statements measuring the perception of participants on various internal and external factors related to the delivery of sustainable products or services. Each respondent chose one of the five options: Strongly disagree, Disagree, Neutral, Agree, Strongly Agree. The statements measure the perception of the participants on six factors: legal, economic, social, psychological, marketing, and geographical and environmental factors.

\subsection{Legal factors}

Survey Question (SQ): Specific laws and/or regulations present challenges to entering the market for your sustainable solutions.

Company responses reveal approximately $80 \%$ of sustainable businesses believe specific laws or regulations act as barriers to entry for sustainable solutions in the UAE market. Whereas only $40 \%$ of the respondents felt specific laws or regulations presented challenges to market entry in their home markets. Another $40 \%$ actually disagreed with the idea specific laws or regulations presented challenges to sustainable market entry in their own countries. In essence, the data suggest respondents felt their home countries offered a more favorable legal environment with respect to entry into their sustainable market sector. Given the UAE's goals regarding sustainability, we found the foregoing result surprising. There are several potential explanations, but the most obvious explanation is the existence of a communication gap between the government's vision, legal policies and the business community. The results from some of our other survey questions evidence this finding.

SQ: Modifications to specific laws and/or regulations would likely lead to operational efficiencies in my sustainable business.

The vast majority of survey respondents believe modifications to specific laws and/or regulations would lead to operational efficiencies in their sustainable business both in the UAE $(92 \%)$ and in their home countries $(80 \%)$. In fact, $35 \%$ of respondents strongly agreed with the statement with respect to the UAE, whereas only $27 \%$ of respondents strongly agreed with the statement for their home country. Again, the data suggest respondents perceive more extensive legal barriers in the UAE than in their home markets.

SQ: Laws and regulations may be needed to help establish and organize the market for my sustainable business.

Similar to the previous survey question, the vast majority of respondents believed additional laws and regulations may be needed to help establish and organize the market for their sustainable business, both in the UAE (92\%) as well as their home countries $(80 \%)$. With respect to the UAE, 
$40 \%$ of the respondents strongly agreed. In comparison, $32 \%$ of the respondents strongly agree to the statement with respect to their home country.

SQ: Incentives exist in the GCC for the establishment and/or operation of my sustainable business.

Survey respondents clearly felt the GCC offered far fewer incentives for sustainable businesses than their home countries. Surprisingly, $43 \%$ of respondents either strongly disagreed or disagreed with the statement incentives for sustainable businesses existed in the GCC, whereas $76 \%$ of respondents strongly agreed or agreed their home country provided incentives for sustainable businesses. One confounding variable is how respondents based in the UAE responded to the home country question. Regardless, the data indicate respondents perceive fewer incentives for sustainable businesses in the GCC region.

\subsection{Marketing Factors}

We all agree with the statement that the heart of business lies in marketing, so the focus on, and the creation of, solid marketing communication is invaluable. Flørenæs [34] based on the conducted research, clearly demonstrated the importance of marketing communication in order to achieve international success. Although marketing communication is dependent on both the product and the industry, the authors indicate that it is crucial for rapid growth in the global arena.

\section{S.Q. Importance of the marketing communication for the international expansion}

The evidence states that all markets have provided overwhelming support to the statement, which shows the confidence on their strategies to communicate with their clients. On the other hand, about $30 \%$ in each market were not clear about their degree of agreement to the statement. This group may not have any specific strategy to communicate and reiterate their past best practices as a routine marketing operation. Both in the home market and in the UAE the companies are following a similar approach to communicate their marketing efforts. However, it is important to note that not a more holistic approach to communication should be implemented.

\section{S.Q. Our brand is well-known in the country as a sustainable brand.}

The research showed that more than $20 \%$ companies have shown disagreement with the statement. Moreover, about eleven percent companies have age less than one year, and about $10 \%$ are in the market for less than three years. The overall trend is towards agreement, but one fourth have opted for the 'neutral' indication lack of confidence on their marketing efforts. Being a sustainable brand is one thing, known as a sustainable brand is another thing. It is very crucial to note the difference between UAE and home market. These discrepancies can be improved with the correct branding of the sustainable solutions.

S.Q. There is enough information for consumers in the country/market to assess the degree of sustainability in our products/solutions.

Results reveal that the evidence from the UAE market is negative, and disagreement to the statement is the reason of weak marketing efforts. The lack of information to the consumers is indicating the gap in the marketing efforts and justifying the objective of the current study to support businesses by advising appropriate data-driven marketing strategy. About $70 \%$ were found disagreeing with the statement in the UAE market. On the other hand, the data about the markets in other countries are showing clear agreement. Although about 30\% were found disagreeing with the statement.

S.Q. Customers of our sustainable products / services are highly sensitive to the price change.

It was found that the economic factor plays an important role and it is realized by the businesses in all markets. High sensitivity means the elasticity of demand is high and smaller change in the price can lead to the larger proportionate change in the demand of sustainable products. In all markets over $70 \%$ have shown the agreement to the statement.

The price sensitivity is a very important issue. When analyzing the market for sustainable solutions, we should understand what is the reason of customer's positive or negative reaction to the 
price change. Falkowski [35] analyzed the relationship between price perception and the willingness to buy a certain product.

According to the Authors this dependence is not direct, because this influence is modified by the consumer's sensitivity to the price, which is always shaped by the experienced context of other prices, so-called reference prices - in our case the non-sustainable product prices.

Thus, the price context can determine one of two states of affairs. It may refer to a price increase, recalling the earlier, lower price of a given product, or to a price reduction, for example, as a price promotion. On the basis of psychophysical research on the perception of price changes, the consumer's sensitivity to the increase was significantly higher than on the reduction, measured by Weber's fraction.

Such a result fits well in the psychological theory of perspective, which emphasizes the asymmetry in the valuation of profits and losses and consists in the fact that loss (increase) of the same absolute value causes greater dissatisfaction than satisfaction caused by profit (reduction).

The above study may suggest that the lack of understanding of the importance of sustainability and the often-related increase in the price of a sustainable product or service causes the negative customer's response to the usually higher price of sustainable products.

S.Q. Our company does not find any difficulty to communicate the 'sustainability' message in the market.

It is evident that in the UAE market the picture is not clear about the degree of agreement or disagreement. Proportion of both respondents supporting and opposing the statement are equal. The proportion of 'neutral' respondents is also $40 \%$ which is very high. On the other hand, international markets the balance goes towards the agreement with the statement. Therefore, the businesses in the markets of other countries are enjoying the convenience of conveying their message, which is not evident in the UAE. The respondents were neutral while answering this question therefore it is difficult to make a certain judgement. However, it is evident that there are some difficulties conveying the message in UAE market.

S.Q. There are bottlenecks in the market which hinder our efforts to communicate with regulatory agencies.

Approximately $70 \%$ of the respondents agreed they find it difficult to communicate with the authorities on the matter of sustainable products in the UAE. This indicates a certain level of obstacles exists in the region which inhibits businesses to communicate their message to regulatory agencies. In comparison, this ratio is only $40 \%$ in other markets. The proportion of 'neutral' responses is very high in the international markets, which is above $50 \%$, whereas in the UAE it is below $30 \%$. Therefore, a data-driven claim supporting the statement can be made about the UAE market.

Aizenman [36], comments that the inefficiencies brought about by the bottleneck often create delays and higher production costs. The bureaucracy can be a strong alert for reducing the bottleneck in the market. Once budget constraints are hardened and credit markets begin to function properly, bottlenecks are likely to become prevalent in the state sector, where the creditworthiness of enterprises is limited by outdated production technologies. Financial market infrastructures ("FMIs"), which facilitate the execution of financial transactions, exhibit such strong economies of scale that they are natural monopolies [37].

\subsection{Economic/Infrastructure Factors}

S.Q. The current infrastructure in the country provides support to our business model.

It was found out the disagreement about the statement for the UAE market, and supports the statement for the other markets of the world. Less than $30 \%$ of respondents in the UAE market are observed supporting the statement, and about $50 \%$ believe that the current infrastructure in the country does not support their business model. In the international markets support goes to the $60 \%$, which indicates that such country has developed the infrastructure encouraging the use and production of sustainable products. 
According to the respondents, is evident that the government needs to develop strategies to become close to the industry for re-orientate the business model from the foreign countries and also, with constant changes the businesses needs to be adaptable and flexible for surviving.

S.Q. I believe that high cost of living curbs our marketing efforts in the market.

Approximately $70 \%$ of the respondents agreed with this statement in the UAE market. The behavior in the international markets is not clear, as $48 \%$ respondents found not clear about the relationship between cost of living and marketing efforts. In such countries where infrastructure support is available the relationship between high cost of living and the marketing efforts may not appear. The introduction of a Value Added Tax (VAT) regime in the UAE impacted on purchasing power and resulted in a sharp increase in cost of living that affect customers purchasing power. According to the respondents, rising cost of living is pressuring their marketing effort, so they need to work much harder to convince consumers to buy their products.

S.Q. Low fuel prices encourage customers not to think about the sustainable products.

Responses provide evidence for another economic factor - the fuel prices. The statement in this section is showing the strong agreement about the relationship between fuel prices and the use of sustainable products. More than $60 \%$ favor the statement in the UAE market, whereas in the context of other markets of the world, the respondents found disagreeing on the statement. Another important aspect is the high proportion of 'neutral' responses in the home market section, which also indicates that some confounding variables in the international markets may not allowing respondents to favor the statement. For example, the fuel prices are very low in those countries and they may have not experienced such relationship. In the UAE the fuel prices have direct effect on the cost of living, and it may affect the frequency of the use of sustainable products. The low fuel prices (on a global scale) are a negative factor that affects the buyer decision process in the UAE market. Pricing is one of the $4 \mathrm{P}^{\prime} \mathrm{s}$ in the marketing mix and it is the only element that brings revenue, it can be altered by the marketers. However, as fuel prices are regulated by the government in the UAE, this factor will remain as a negative one in the way of sustainable thinking.

S.Q. High electricity tariffs can encourage customers to think about sustainable solutions.

The case of electricity tariffs is not very different from the fuel prices. Both are an important component of the cost of living. Therefore, the strong agreement (about 70\%) is observed in all markets about the statement. The response pattern of the foreign markets is different in the case of electricity compared with the case of fuel prices

The cost of living in the country increased after the introduction of the VAT. According the WorldData.info (2019), the United Arab Emirates can provide itself completely with self-produced energy. However, innovate using new clean sources is the target of the internal policies in the country. The total production of all electric energy producing facilities is $122 \mathrm{bn} \mathrm{kWh}$, also $108 \%$ of own requirements [38].

S.Q. Dollar parity (exchange rate) is a favorable factor to sell our products / solutions in this country.

Results show the lack of clarification about the statement among respondents. More than $50 \%$ respondents have marked 'neutral' option. The nature of statement is technical and may not be understood by the respondents how to relate term parity (exchange rate) with the sale of their products. Therefore, no conclusion can be drawn clearly in this section. However, some degree of agreement can be observed in all markets which is larger in the UAE.

S.Q. A tax holiday for the use of sustainable products can support our business.

Responses show that about $45 \%$ of respondents are not willing to respond on the statement. Although, about $46 \%$ have shown the agreement with the statement. Similar pattern is observed in the foreign markets.

5.5. Social Factors

S.Q. Most customers in the market still have a traditional mindset towards sustainability, which does not encourage them to use sustainable products/solutions.

The data has provided strong support on the statement in all markets. The agreement in the UAE market is stronger (about 90\%) than the foreign markets (about 60\%). The habits or convenience in 
the use of non-sustainable products encourage the traditional mindset. This mindset is evident from the UAE data that respondents strongly support the statement.

S.Q. The proportion of expatriates (expatriates) to the local population impacts the sale of sustainable solutions in my target markets.

The figure 5 has explained another social factor - the demographic composition. The UAE market data is very strongly supporting the statement, whereas in the foreign markets such composition may not exist, and weaker support was observed. The demographic imbalance was considered one of the reasons affecting the sale of sustainable products in UAE. What are those factors in the demographic compositions which can influence the sale is not clear? Therefore, the evidence of the presence of confounding variables is witnessed from the data. About $60 \%$ were found strongly supporting the statement in UAE and about $37 \%$ in the foreign markets.

\section{UAE Market}

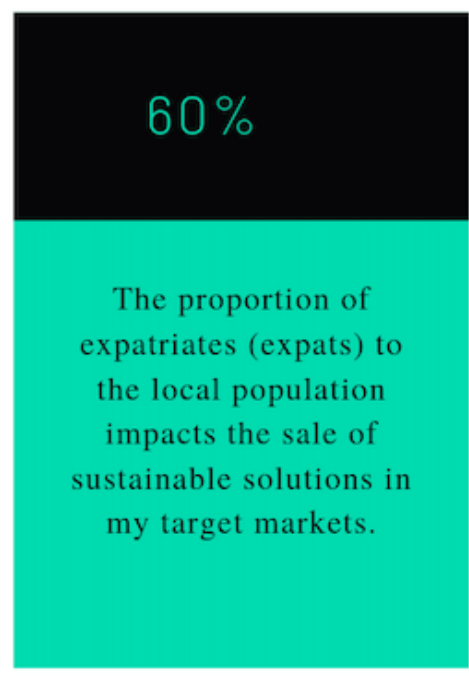

\section{Home Market}

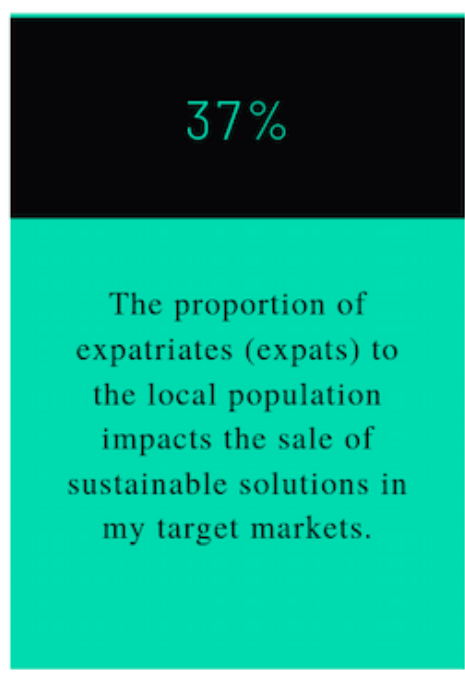

Figure 3. Demographic composition

S.Q. There is a common mindset that implementing a sustainable solution will involve a complex procedure.

The Figure 6 has provided another insight on the social and psychological factor-the common mindset of the society. All markets were found strongly supporting the statement. The procedural complexity in the implementation of the sustainable solutions is the outcome of such a mindset. More than $60 \%$ in the UAE and above $40 \%$ in other markets of the world have shown strong agreement on the statement. The data shows the perception is, that implementation of sustainable solution might need to bring in some difficult reconstruction in the present system. 


\section{UAE Market}

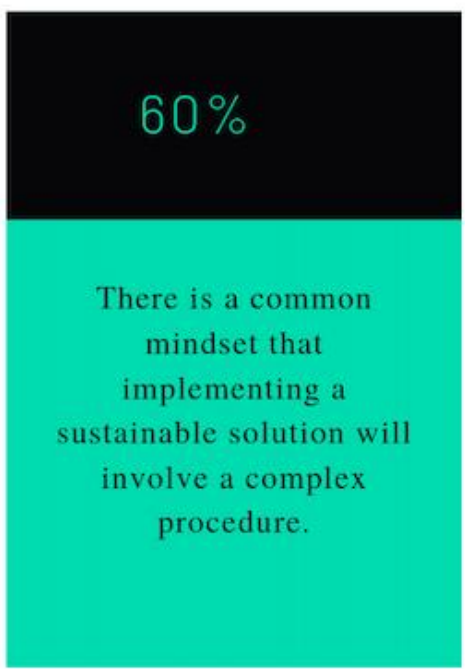

\section{Home Market}

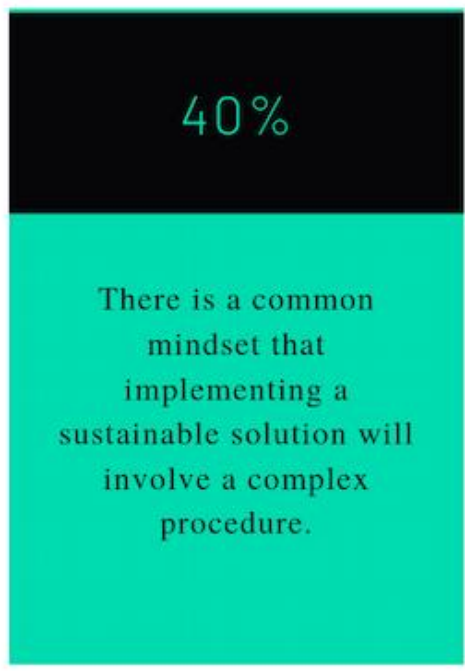

Figure 4. Mindset in UAE and Home market

S.Q. There is a common perception that implementing a sustainable solution will require additional resources.

According to the data, a clear-cut agreement in all markets is evident. In the UAE the agreement is very strong and exceeding $70 \%$, and in other markets it is about $60 \%$. Respondents believe that people feel that some additional resources are required which may change their current living style or domestic infrastructure before implementing the sustainable solutions.

S.Q. There is a perception that environmental problems are long term, so no immediate solution could be applied.

According to more than $50 \%$ respondents, consumers do not realize the sustainability issues as very urgent. This mindset is supporting the individualistic approach and exhibit that collectivism lacks in such countries towards sustainability. The pattern is similar around the world.

S.Q. An abundance of resources in the country discourages or dampens people from feeling an urgency towards sustainable solutions.

Majority respondents are agreeing that the no urgency were found among the population about the seriousness of the sustainability. The availability of non-sustainable products are in abundant and very much embedded into the current social and geographical infrastructure, which do not encourage a common person towards the use of sustainable environment friendly products. In the UAE, more than $70 \%$ were found agreeing the statement, whereas in the other markets around the world such agreement is about $50 \%$.

S.Q. The natural environment in the country restricts the use of sustainable products.

The results provided the evidence about the impact of the environmental and geographical factors on the sale of sustainable solutions. The similar pattern was found in all markets. Majority of respondents do not consider natural environment of the country which restrain the use of sustainable products. About $50 \%$ respondents have shown disagreement for the statement. It is evident that sustainability protects our natural environment, however according to both home market and UAE market, geographical and natural environment do not curb the implementation and use or sustainable products

S.Q. An awareness campaign can develop the sustainable mindset in the country.

Respondents in this study have no doubt about the importance of the awareness campaign to develop the sustainable mindset among the population. Data has shown the support of more than 
$90 \%$ in the UAE and about $100 \%$ in the context of foreign markets. The data indicates there is an immediate need to develop more awareness campaigns on the emerging issues like sustainable living, environmental friendliness and global warming. These campaigns will enable consumers to think about their consumption preferences and ultimately their lifestyles.

S.Q. Some sustainable products/solutions are status symbols in the market.

More than 60\% support is evident in the UAE and other markets. Respondents believe that there are some sustainable products in the country which has become a status symbol for many users. Some reasonable level of neutral response is also found in all markets.

Is notable that communication is a crucial point for informing the population and investors regarding sustainable products and actions. The social media should be used to promote sustainable actions and products for achieving different kinds of social stratification or level.

S.Q. There are insufficient channels in the client organizations to communicate about sustainability issues.

The clear evidence is found for the agreement towards the statement in all markets. The similar pattern shows about the perception about the insufficient channels in the users' organizations. More than $60 \%$ of respondents are agreeing the statement.

S.Q. Sustainable solutions are expensive compared to the other non-sustainable solutions/products in the market.

Respondents believe that sustainable solutions are expensive compared to the non-sustainable products/solutions. More than $50 \%$ are found supporting the statement. About $20 \%$ respondents were found disagreeing with the statement, whereas about $20 \%$ were also opted for the 'neutral' response.

\subsection{Open-Ended Qualitative Data}

The respondents attributed the difficulty of the businesses with the current economic situation in the country by relating the cyclical pattern with the market of sustainable products. Some also believed that the current economic slowdown is an opportunity to enter the market as it will increase the future payoff. Some respondents felt favorable import tariffs rates encouraged them to earn profits from the UAE market. Optimism was also observed among the respondents as they were hopeful about the future of sustainable products. They also found comparing the past market situation with the current conditions and considered that the current business environment has improved over the years in support of the sustainable product solutions. Respondents also believed the market can improve by introducing new laws and regulations supporting the use of sustainable products in the region. Finally, respondents also considered the importance of the availability of information about the market, consumer awareness campaign, and encouragement of sustainable business practices in the region.

\section{Discussion}

In the following section, we discuss our research hypothesis in the light of the data we collected.

H1: Companies endeavoring to compete in the sustainable market sector believe the UAE legal environment is favorable.

Based on the evidence collected, we rejected the H1 hypothesis. The participants in our study felt the legal environment in the UAE was less favorable than other (their home) jurisdictions. Moreover, a majority of the participants believed a lack of proper information about their operations and processes was the cause of the unfavorable legal environment in the country, and that the legal environment could be improved by providing additional information to the authorities about the nature of the business. The evidence strongly suggests a gap in information being shared between important market stakeholders. A survey of legal regulations related to sustainable development enacted by the UAE federal government, along with various emirates, demonstrates the importance government officials place on sustainability in the development of the country. The fact companies delivering sustainable solutions still believe legal barriers pose significant challenges to their 
respective enterprises suggests a misalignment between the government's sustainable development agenda and existing rules and regulations. Further research is necessary to determine the specific legal barriers faced in each sector and whether companies offering sustainable solutions are in fact correct in their perception of the current legal regulations in their sectors.

On a positive note, the evidence suggests companies implementing sustainable solutions are willing to work hand in hand with the authorities (on their home market as well as on the foreign markets) to cover the gap and create implementing policies that will support more sustainable operations. The findings show a positive attitude is prevelent among responsible firms to cooperate with authorities in creating business-friendly market environment with respect to the sustainable products or services.

An important role in solving this situation may also have educational marketing communication used on both sides of market stakeholders. It seems to us that Executive Marketing Educational Programs offered by universities can support better communication. Another appropriate platform for cooperation between business and government administration units are the Chambers of Commerce and Industry - non-profit organizations whose mission is to represent, support and protect the interests of the business community.

H2: Companies are considering economic, socio-cultural and environmental factors to be highly significant in sustainable development of UAE market.

Alignment in the mindset of business and customer / consumer

The whole idea of using less of resources is taken as cut back in the comfort level of living and make adjustments in daily life. This is the basic mindset which is creating the difference of consumers being at the same pace with business. The way the message is communicated with the consumer is keeping a gap in the alignment of mindset of business and consumer, as the thought of using less resources is either an unwelcome message or is ignored in this socio-cultural scenario. The study has produced enough evidence to accept the hypothesis that economic factors are causing barriers in the promotion of sustainable solutions in the country. The findings suggest that lack of economic incentives prevails in the region which restrict business activities of sustainable products and services. The sensitivity of the customers towards price change is high and they relate their cost of living with the use of sustainable products. Many respondents also believe that consumers found sustainable solutions expensive compare to the other non-sustainable substitutes.

Similarly, infrastructure in the country does not support the sale of sustainable products.

Social factors play an important role in the market of the sustainable solutions. Social factors are driving through the local regional culture. Companies are not very clear in accepting that there is no bottleneck in the market when communicating with authorities about their products. Large demographic imbalance invites the attention towards the presence of confounding factors in demographic structure. Traditional mindset also restricts the use of sustainable solutions. The evidence provides support that the social factors are causing barriers in the selling of sustainable products or services.

\section{H3: Psychological barriers inhibit the implementation of sustainable solutions in the UAE.}

Number of psychological factors prevails in the society of the UAE which influence the mindset of the consumers in the region. The data in this study has provided evidence that psychological factors are causing barriers in the sale of sustainable products in the country. Affluent class is considered to be using more resources. This leads to products being linked to status quo and hence cannot be not consumed. The psychological barrier to think for long term creates a denial in the mind of society to feel the need of urgency and seriousness towards sustainable solutions. The abundance of non-sustainable resources in the market is not allowing the society foresee the requirement for sustainable solutions. 
H4: The conventional marketing approach is hindering the ability to implement successful sustainable solutions in the UAE.

Marketing factors are key elements of the success of the businesses dealing in the sustainable products. This study has provided enough evidence to accept the hypothesis that traditional marketing factors are causing barriers in the implementation of sustainable solutions. The data has explained that the success of business depends on the degree of awareness about sustainability among both the business and customer population. Marketing efforts of the companies have produced encouraging results for many participating companies in this study.

Research shows that there is a need to change the way of thinking on both sides of market stakeholders. When implementing a new approach to marketing - Sustainable Marketing - it should be made clear to consumers that the time has come to change consumption habits. Sustainable Marketing also has an important role in building responsible awareness within the organization among those who are responsible for the development and production of new products and services.

The respondents are also realizing the importance of the awareness campaign to educate potential users of sustainable solutions.

The marketing communication technology which lubricate the flow of information among stakeholders of the sustainable products is playing an important role. The modern technological solutions and business processes should be sustainable and environmentally friendly.

The research highlighted that geographical and environmental factors are playing a vital role in the success of business activities dealing in the sustainable products as well - which means that these factors should be taken into account in the preparation of marketing strategy for responsible market solutions.

Majority of respondents do not consider environmental factors are causing any hindrance in the sale of sustainable products. Therefore, in our opinion, there is also the role of Sustainable Marketing to implement marketing communication projects that educate both the producer and the consumer about the importance of the environment in the implementation of new responsible, sustainable market solutions.

\section{Conclusion}

Above analysis has provided enough insight into the matter and provide support to emphasize the role of effective marketing strategy that can encompass the underlying factors of the success of businesses dealing in the sustainable solutions. The key factors are legal, economic, psychological and social which share larger consensus among the participating companies. Revision of legal framework is recommended along with the awareness campaign to educate the citizens in the region for the use of sustainable solutions. To achieve a responsible and sustainable society, basic changes in everyone's behavior as well as basic values should be promoted. Environmental psychologists are in the debate of searching the most important variables to bring about this change, which could be changes in values, attitudes, beliefs and norms. This is also important that users will not feel the urgency unless they would not be able to relate it with the quality of life. Hence, a suggestion to business is to align the products and market strategy to the mindset of the population and match with the status symbol. Sustainable solutions should also be developed in such a manner that they can be offered on the competitive prices. Technology can play a vital role and by applying modern techniques of artificial intelligence the cost-effective solutions can be produced.

An important role in the implementation of sustainable mindset, in our opinion, is the cooperation between business and education. Such cooperation opens up new space in shaping the future and implementing solutions that are to provide prosperity for coming generations. Research in this area attempts to build up a psychological mindset of the society towards the use of sustainable resources by eliminating the reactance to the changes which they find undesirable or counterproductive. Also, to suggest the business to prepare positive motivating strategies for the 
consumers which removes the resistance from the society to postpone the actions till an irreversible damage is caused to the environment.

1. Awareness/Education about government policies and initiatives.

2. Changing the conventional marketing approach into responsible marketing practices by implementing educational programs on all levels from KG to higher education.

Sustainability is a complex social and business issue - the role of academia is to discuss how things happen and research for the solutions in the social, economic, political and psychological mechanisms. The academia is also responsible for searching for solutions and presenting new management and decision-making processes, new organizational structures, leadership strategies new visions. Sustainable marketing plays here the significant role, as a powerful theoretical and practical institution, responsible marketing might change the entrenched values and practices that have helped produce the present sustainability crisis.

Education in the field of sustainable marketing development is essential for future generations to appreciate, understand and critically think about complex environmental, social and economic problems [39]. We agree that educational programs about sustainability should include discussions on the implications of ethics, alternative worldviews, the role of humans in ecosystems and finally vision of the future. Curriculum in sustainability is not only about planning the study, courses and students activities, but above all it is the reason for building a new future, creating a community ready to implement what they have learned and contribute to the development of more sustainable opportunity.

The responsibility of academia is the future - what the students will learn about sustainability is how they will influence the upcoming world.

Education regarding sustainability should address its programs to all levels - starting with education in kindergartens and ending with doctoral programs.

To be successful, decision makers should ensure that sustainability education is a priority. At this stage we found that at the level of governmental strategies sustainability occupies a significant place, while there is a lack of commitment at the educational implementation and operational level.

There is not much sizeable recognition of sustainability marketing issues among young generation of marketers. Future decision makers need to be aware about this emerging issue starting from KG. Education policy makers have a huge role to play at this stage to incorporate sustainability at the curriculum. Sustainability should not be addressed not only at business schools but also across all disciplines. Future marketers are responsible for creating products and services that will be impacted from sustainable socio-cultural and economic environment preserving the world in which they live.

3. Implementation of sustainable mindset, in our opinion, is the cooperation between business and education.

4. Cooperation between business and research and educational institutions.

Research \& Development projects are fundamental to link universities and businesses to transfer and manage knowledge. The cooperation between academic institutions and industries could motivate innovations or support academic research projects and solve business issues. The partnership between university-business should be amplified to the 'Triple Helix Model' universityindustry-government to foster economic and social development at local, national and international levels [40]. The potential to develop R\&D towards intellectual property (IP) open in the industry clusters to be taken broader: as creators, transmitters and interpreters of new ideas and transfer knowledge as sources of human capital. Determined types of interactions facilitated the exchange in triple perspective through cooperative research (Problem solving relation); exchanging knowledge management concerning publications, prototypes, patents, technology licensing, faculty consultation, students internship, incubation services and others; to facilitate the relation of university staff and business community through conferences and meetings, entrepreneurship centers, promoting personnel exchange and other research activity. 


\section{References}

1. Seretny M., Seretny A. Sustainable Marketing - a New Era in the Responsible Marketing Development. Foundations of Management, 2012, Volume 4 (2).

2. Batra R., Ymer H. The road ahead - growing momentum in corporate responsibility reporting in the UAE, KPMG Lower Gulf Limited, 2017.

3. Wendling, Z. A., Emerson, J. W., Esty, D. C., Levy, M. A., de Sherbinin, A., et al. (2018). 2018 Environmental Performance Index. New Haven, CT: Yale Center for Environmental Law E Policy.

4. Hogevold N., Svensson G., Wagner B., Petzer D., Klopper H., Sosa V. J., Padin C., Ferro C. Sustainable Business Models: Corporate reasons, economic effects, social boundaries, environmental actions and organizational challenges in sustainable business practices. Baltic Journal of Management, 2014, Volume 9 (3), pp. 357-380.

5. Szczepańska-Woszczyna, Katarzyna \& Pysz, Joanna. Sustainable Business Development Through Leadership in SMEs. Economics and Management, 2016, Volume 8, pp. 57-69.

6. Porter, M. E., \& Kramer, M. R. Strategy and Society: The Link between Competitive Advantage and Corporate Social Responsibility. Harvard Business Review, 2007, Volume 84 (12), pp. 78-92.

7. Milla, C. A., \& Mataruna Dos-Santos, L.J. Social media preferences, interrelations between the social media characteristics and culture: a view of Arab nations. Asian Social Science, 2019, Volume 15 (6), pp. 71-77.

8. Azeem, M. and Mataruna, L. Identifying factor measuring collective leadership at academic workplaces. International Journal of Educational Management, 2019, Volume 33 (6), pp. 1316-1335.

9. Azeem, M.; Mataruna-Dos-Santos, L.J.; Moalla, R.B.A.; Kaleem, M.M. Confirmatory Model of the Workplace Creativity in Higher Education Muhammad. International Journal of Recent Technology and Engineering, 2019, Volume 8 (2), pp. 2277-3878.

10. Goehrig, R. The role of leadership in building high performing, sustainable organizations. Government Finance Review, 2008, Volume 24 (6), pp. 6-14.

11. Mataruna-Dos-Santos, L.J., Zardini-Filho, C.E., \& Cazorla, A. Youth Olympic Games: Using marketing tools to analyse the reality of GCC countries beyond Agenda 2020. Journal of Human Sport and Exercise, 2019, Volume 14 (3), pp. S391-S411.

12. Schneider, S; Clauss, T. Sustainable business models: Opportunities and challenges for development and innovation. ISPIM Innovation Conference, Vienna, Austria, June,2017.

13. Svejvig, P., Geraldi, J., \& Grex, S. Accelerating time to impact: Deconstructing practices to achieve project value. International Journal of Project Management, 2019, 37(5), 784-801.14.

14. Goodreads, Available Online: https://www.goodreads.com/author/quotes/9810.Albert Einstein (accessed on 15.06.2019)

15. Wackernagel, M., Monfreda, C., \& Deumling, D. . Ecological footprint of nations: November 2002 update. Redefining Progress. Sustainability Issue Brief. November

16. Chemers, M., Oskamp, S., \& Constanzo, M. Diversity in organizations: New perspectives for a changing workplace. Sage Publications, 1995, Volume 8.

17. Oskamp, S. A sustainable future for humanity? How can psychology help? American Psychologist, 2000, Volume 55 (5), pp. 496.

18. Kassel K., Rimanoczy, I., Mitchell, S.F. The sustainable mindset: connecting being, thinking and doing in management education. Academy of Management Proceedings, 2017, Volume (1).

19. WCED, S. W. S. Our common future. World commission on environment and development, 1987, Volume 17, pp. 191.

20. Schmuck, P., \& Schultz, P. W. Sustainable development as a challenge for psychology. In Psychology of sustainable development. 2002, pp. 3-17. Springer, Boston, MA.

21. Bullard, R. D., \& Johnson, G. S. Environmentalism and public policy: Environmental justice: Grassroots activism and its impact on public policy decision making. Journal of Social Issues, 2000, Volume 56 (3), pp. 555-578.

22. Seligman, M. E., \& Csikszentmihalyi, M. Positive psychology: An introduction. American Psychological Association, 2000, Volume 55 (1), pp. 5.

23. Seretny M., Sustainable Management - Marketing Perspective, evidence, determinants, manifestations. Warsaw University of Technology Publishing House, 2018.

24. Wind J. Y. Rethinking marketing: Peter Drucker's challenge. Journal of the Academy of Marketing Science, 2009, 37(28). 
25. Gordon, R., Carrigan, M., \& Hastings, G. A framework for sustainable marketing. Marketing Theory, 2011, Volume 11 (2), pp. 143-163.

26. Kotler P., Kartajaya H., Setiawan I., Marketing 3.0, from Products to Customers to the Human Spirit, John Wiley \& Sons, Inc., Hoboken. 2010

27. Nielsen Global Sustainability Report. Available online: https://www.nielsen.com/content/dam/nielsenglobal/dk/docs/global-sustainability-report-oct-2015.pdf. Accessed on (17 February 2019)

28. Barral V. Sustainable Development in International Law: Nature isepiand Operation of an Evolutive Legal Norm. European Journal of International Law, 2012, Volume 23 (2), pp. 377-400.

29. UAE and the 2030 agenda for sustainable development excellence in implementation: executive summary (2018) in Voluntary National Review UN High Level Political Forum 2018, issued by National Committee on Sustainable Development Goals.

30. Qu, S. Q., \& Dumay, J. The qualitative research interview. Qualitative research in accounting \& management, 2011, Volume 8 (3), pp. 238-264.

31. Fontana, A., \& Frey, J. H. The interview: From neutral stance to political involvement. 2005.

32. R Core Team. R: A language and environment for statistical computing. R Foundation for Statistical Computing, Vienna, Austria. 2013.

33. Klewitz J., Hansen E.G. Sustainability-oriented innovation of SMEs: a systematic review. Journal of Cleaner Production, 2014, Volume 65, pp. 57-75.

34. Flørenæs C., Winther D.H., Kenneth W. H. A qualitative study regarding the importance of marketing communication for international expansion among Norwegian entrepreneurial companies. Series of Masteroppgave/UIS-SVHH/2016; University of Stavanger, Norway.2016.

35. Falkowski A., Mackiewicz R. Psychological aspects of price sensitivity: the perspective of benefits and losses. Marketing and Market, 2015, Volume 1, pp. 8-18.

36. Aizenman, J. and Isard, P. Production bottlenecks and congestion externalities during the transition to a market economy. International Review of Economics \& Finance, 1996, Volume 5 (3), pp. 225-241.

37. Chang, F. Financial Market Bottlenecks and the 'Openness' Mandate. George Mason Law Review. 2015. Vol. 23, 2015 Forthcoming; U of Cincinnati Public Law Research Paper Series No. 15.06.

38. WorldData.info. Energy consumption in the United Arab Emirate. 2019. Available online: https://www.worlddata.info/asia/arab-emirates/energy-consumption.php. Accessed on (13 May 2019)

39. Kemper, J.A.; Hall, C.M.; Ballantine, P.W. Marketing and Sustainability: Business as Usual or Changing Worldviews. Sustainability, 2019, Volume 11, pp. 780.

40. Leydesdorff L. Etzkowitz H. Triple Helix of innovation: Introduction. Science and Public Policy, 1998, Volume 25 (6), pp. 358-364. 